\title{
Stomatal conductance bear no correlation with transpiration rate during their diurnal variation under high air humidity
}

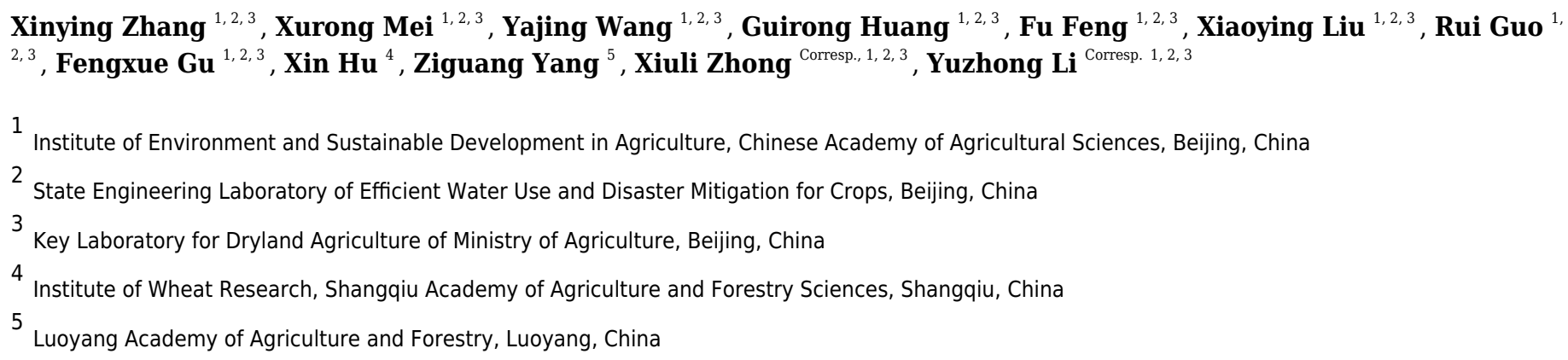

A Good understanding of the response of photosynthesis rate $\left(P_{\mathrm{N}}\right)$ and transpiration rate $(T r)$ to stomatal alteration during the diurnal variations is important to cumulative photosynthetic product and water loss of crops. Six wheat genotypes were studied for two years with pot cultivation in rain-shelter. Among different genotypes, stomatal conductance $\left(g_{\mathrm{s}}\right)$ was significantly correlated with both $P_{\mathrm{N}}$ and $T r$. But for each genotype, though $g_{\mathrm{s}}$ was significantly correlated with $P_{\mathrm{N}}$ regardless of relative air humidity $(\mathrm{RH})$ status and it was also significantly correlated with $\operatorname{Tr}$ under lower $\mathrm{RH}(\mathrm{LRH}, 15.4 \%)$ and moderate $\mathrm{RH}(\mathrm{MRH}, 28.3 \%)$, it was not correlated with $\operatorname{Tr}$ under higher $\mathrm{RH}(\mathrm{HRH}, 36.7 \%)$ during the diurnal changes. The conditional correlation between $g_{s}$ and $\operatorname{Tr}$ of wheat evoked new thinking on the relationships among $g_{\mathrm{s}}, P_{\mathrm{N}}$, and Tr. Path analysis was further carried out to clarify the correlations of $g_{s}$ with the 4 atmospheric factors, that of $\operatorname{Tr}$ with $g_{s}$ and the four factors, and the direct and indirect effects of the factors, during their diurnal dynamic variation. The effects of these factors on $g_{s}$ or $\operatorname{Tr}$ were related to $\mathrm{RH}$. All the 4 factors had a much higher correlation with $g_{s}$ under $\mathrm{HRH}$ than that under $\mathrm{LRH}$ and $\mathrm{MRH}$. Air temperature (T) had a rather higher direct effect than $\mathrm{RH}$ and photosynthetically active radiation (PAR). And the other factors had a much higher indirect effect on $g_{s}$ through vapor pressure deficit (VPD) and T. Transpiration rate was highly correlated with $g_{\mathrm{s}}$ under $\mathrm{LRH}$ and $\mathrm{MRH}$, with $g_{\mathrm{s}}$ having a higher direct effect on it. In comparison, $\operatorname{Tr}$ was not correlated with $g_{\mathrm{s}}$ under HRH but highly correlated with the atmospheric factors, with $\mathrm{T}, \mathrm{RH}$, and PAR having a higher indirect effect through VPD. 


\section{Stomatal conductance bear no correlation with transpiration rate}

\section{2 during their diurnal variation under high air humidity}

3

4 Xinying Zhang ${ }^{1,2,3}$, Xurong Mei ${ }^{1,2,3}$, Yajing Wang ${ }^{1,2,3}$,Guirong Huang ${ }^{1,2,3}$, Fu Feng ${ }^{1,2,3}$, Xiaoying

5 Liu $^{1,2,3}$, Rui Guo ${ }^{1,2,3}$, Fengxue $\mathrm{Gu}^{1,2,3}$, Xin $\mathrm{Hu}^{4}$, Ziguang Yang ${ }^{5}$, Xiuli Zhong ${ }^{1,2,3}$, Yuzhong Li ${ }^{1,2,3}$ 6

${ }^{1}$ Institute of Environment and Sustainable Development in Agriculture, Chinese Academy of Agricultural Sciences, Beijing 100081, China

${ }^{2}$ State Engineering Laboratory of Efficient Water Use and Disaster Mitigation for Crops, Beijing 100081, China

${ }^{3}$ Key Laboratory for Dryland Agriculture of Ministry of Agriculture, Beijing 100081, China ${ }^{4}$ Institute of Wheat Research, Shangqiu Academy of Agriculture and Forestry Sciences, Shangqiu, 476000, China

${ }^{5}$ Luoyang Academy of Agriculture and Forestry, Luoyang, 471022, China

Corresponding author:

Xiuli Zhong ${ }^{1,2,3}$, Yuzhong $\mathrm{Li}^{1,2,3}$

Street address: Beijing, 100081, China

E-mail address: zhongxiuli@caas.cn; liyuzhong@,caas.cn 
Abstract

A Good understanding of the response of photosynthesis rate $\left(P_{\mathrm{N}}\right)$ and transpiration rate $(T r)$ to stomatal alteration during the diurnal variations is important to cumulative photosynthetic product and water loss of crops. Six wheat genotypes were studied for two years with pot cultivation in rain-shelter. Among different genotypes, stomatal conductance $\left(g_{\mathrm{s}}\right)$ was significantly correlated with both $P_{\mathrm{N}}$ and $T r$. But for each genotype, though $g_{\mathrm{s}}$ was significantly correlated with $P_{\mathrm{N}}$ regardless of relative air humidity $(\mathrm{RH})$ status and it was also significantly correlated with $\operatorname{Tr}$ under lower RH (LRH, 15.4\%) and moderate RH (MRH, 28.3\%), it was not correlated with $\operatorname{Tr}$ under higher RH (HRH, 36.7\%) during the diurnal changes. The conditional correlation between $g_{\mathrm{s}}$ and $\operatorname{Tr}$ of wheat evoked new thinking on the relationships among $g_{\mathrm{s}}, P_{\mathrm{N}}$, and $T r$. Path analysis was further carried out to clarify the correlations of $g_{\mathrm{s}}$ with the 4 atmospheric factors, that of $\operatorname{Tr}$ with $g_{\mathrm{s}}$ and the four factors, and the direct and indirect effects of the factors, during their diurnal dynamic variation. The effects of these factors on $g_{\mathrm{s}}$ or $\operatorname{Tr}$ were related to RH. All the 4 factors had a much higher correlation with $g_{\mathrm{s}}$ under HRH than that under LRH and MRH. Air temperature (T) had a rather higher direct effect than RH and photosynthetically active radiation (PAR). And the other factors had a much higher indirect effect on $g_{\mathrm{s}}$ through vapor pressure deficit (VPD) and T. Transpiration rate was highly correlated with $g_{\mathrm{s}}$ under LRH and MRH, with $g_{\mathrm{s}}$ having a higher direct effect on it. In comparison, $\operatorname{Tr}$ was not correlated with $g_{\mathrm{s}}$ under HRH but highly correlated with the atmospheric factors, with T, RH, and PAR having a higher indirect effect through VPD.

Keywords: stomatal conductance; relative air humidity; net photosynthesis rate; transpiration rate; wheat genotypes

\section{INTRODUCTION}

The water shortage has been the most significant factor restricting plant growth and crop productivity with a deepening water-resource crisis worldwide. Wheat (Triticum aestivum L.) is one of the main crops consumed by humans and is cultivated in different environments. Only less than $30 \%$ of the rainfall occurs during the wheat growing season in the North China Plain (NCP), the main wheat production region of China, which meets only about $25-40 \%$ of the water requirements of wheat. As a result, more than $70 \%$ of the irrigation water is used for winter wheat (Mei et al. 2013). Irrigation usage for wheat threatens the sustainability of the groundwater resource (Zhang, Pei \& Hu 2003). Therefore, how to conserve soil water to enable sustainable crop production and maximize harvest of fields are becoming the main goals for many efforts of 
agriculture researchers.

Stomata, the gateway through which vapor and $\mathrm{CO}_{2}$ pass, play an important role in regulating both photosynthesis and transpiration. Low stomatal conductance $\left(g_{\mathrm{s}}\right)$ results in low net photosynthesis rate $\left(P_{\mathrm{N}}\right)$ by restricting $\mathrm{CO}_{2}$ uptake (Farquhar \& Sharkey 1982), while high $g_{\mathrm{s}}$ benefits higher $P_{\mathrm{N}}$ but at a greater expense of water loss via transpiration (Lawson \& Blatt 2014). The ability of stomata to exert rapid control of their aperture to minimize water loss while maintaining $\mathrm{CO}_{2}$ uptake is one of the primary evolutionary mechanisms that has allowed terrestrial plants to survive and spread in an otherwise desiccating atmosphere (Hetherington \& Woodward 2003). A good understanding of the response and behavior of stomata and transpiration in winter wheat is in urgent need of water saving through the pathway of cultivar adoption and agricultural practices. Stomata adjusts aperture in response to diverse external stimuli, such as vapor pressure deficit (VPD) (Devi, Sinclair \& Vadez 2010; Leonardi, Guichard \& Bertin 2000), relative air humidity (RH) (Bakker 1991a; Bakker 1991b; Merilo et al. 2018; Suzuki et al. 2015; Talbott, Rahveh \& Zeiger 2003), soil moisture (Belko et al. 2012; Kholová et al. 2010a; Kholová et al. 2010b), air temperature (T) (Haque et al. 2017; Hetherington \& Woodward 2003), photosynthetic photon flux density (PPFD) (McAusland et al. 2016), and $\mathrm{CO}_{2}$ (Yoshimoto, Oue \& Kobayashi 2005). These atmospheric factors continually vary at diurnal and seasonal rhythms (Assmann \& Wang 2001). Besides, the circadian clock was reported to control $g_{s}$ responses partly at least over the diurnal period (Dodd et al. 2005; Hassidim et al. 2017), with phase of the circadian clock adjusting to environmental cues, such as T and PPFD, etc. (de Dios et al. 2016; Yin \& Johnson 2000). The majority of these studies were conducted with controlled experiments. Few studies were performed utilizing different gradients of natural conditions, which may be largely different from those carried out in climate chambers or green houses. Besides, these researches seldom laid stress on how the influencing factors affect $g_{\mathrm{s}}$ during the diurnal dynamic change.

Our previous study found that RH played an important role in determining the diurnal $g_{\mathrm{s}}$ pattern of wheat. All tested genotypes under lower RH (LRH, 15.7\%) and most genotypes under higher RH (HRH, 40.7\%) displayed a gradual decline pattern from morning through the afternoon. All genotypes presented a single-peak curve pattern under moderate RH (MRH, 28.3\%), but the peak time differed among genotypes (Zhang et al. 2019). Base on the previous research, this study aims at 1) clarifying how the influencing factors contribute to the diurnal variation of $g_{\mathrm{s}}$ along with transpiration rate $(\mathrm{Tr})$ of wheat under different $\mathrm{RH}$ and soil moisture regimes; 2) making clear how $P_{\mathrm{N}}$ and $\operatorname{Tr}$ of wheat are correlated with $g_{\mathrm{s}}$ during the diurnal change under different regimes of soil moisture and $\mathrm{RH}$. A deep understanding of the stomata and transpiration traits of wheat, the influencing factors, and their effect on $P_{\mathrm{N}}$ and $\operatorname{Tr}$ under 
107

108

109

110

111

112

113

114

115

116

117

118

119

120

121

122

123

124

125

126

127

128

129

130

131

132

133

134

different conditions have great implications for saving water through cultivars and agricultural practices.

\section{MATERIALS AND METHODS}

\subsection{Plant materials}

Six winter wheat genotypes, Jinmai 47, Chang 6878, Jing 411, Zhoumai 18, Lankaoaizao 8, and 12 Song 1 were used as materials, with the names and associated details being listed in Table 1. The 6 genotypes were selected from wheat germplasm nursery affiliated to Luoyang Academy of Agriculture and Forestry, located in Henan Province, China. In April 2016, the jointing stage of winter wheat, stomatal conductance was measured in three replications of different genotypes in the nursery under rain-fed and well-watered conditions. According to the data collected from 9:00 to 11:00am, six genotypes, which were in a wide spectrum of $g_{\mathrm{s}}$ from very low to rather high value in the two water conditions, were tentatively selected as materials.

\subsection{Growth conditions}

The experiments were carried out at Shunyi Scientific Experimental Station, Institute of Environment and Sustainable Development in Agriculture, Chinese Academy of Agricultural Sciences, Beijing, China $\left(40^{\circ} \mathrm{N}\right.$ and $116^{\circ} \mathrm{E}$, altitude $\left.34 \mathrm{~m}\right)$ in $2017-2018$ growing seasons of winter wheat. The precipitation and air temperature of every month during the growing season are presented in Figure 1. Pot cultivation was adopted in this experiment. Polyvinyl chloride (PVC) pots were $30 \mathrm{~cm}$ depth and $35 \mathrm{~cm}$ in diameter, with a drainage hole on the bottom. The pots were filled with $16 \mathrm{~kg}$ plow layer soil, which was sieved through a $5 \mathrm{~mm}$ sieve and then fully mixed. The soil nutrients were determined as $0.109 \mathrm{~g} / \mathrm{kg}$ of total nitrogen, $14.4 \mathrm{~g} / \mathrm{kg}$ of organic matter, $24.5 \mathrm{mg} / \mathrm{kg}$ of available phosphorus, $106 \mathrm{mg} / \mathrm{kg}$ of available potassium, and soil pH was 7.7.

For each genotype, 6 pots were planted for two water treatments and three replications. Twenty wheat seeds were sown in each pot on October 5, 2017. Thirteen uniform seedlings were kept for overwintering, with the slender ones being removed on $30 \mathrm{~d}$ after emergence. After recovering in the spring, 10 uniform seedlings were eventually selected and kept as materials, with the unqualified ones being eliminated. 


\subsection{Air humidity and soil water treatments}

The treatments were different regimes of air humidity and soil water. The environmental RH gradient was taken as air humidity treatments. April 13, 28 and May 6, 2018, which were LRH (15.4\%), MRH (28.3\%), and HRH (36.7\%) respectively, but similar in T and PAR were specifically selected. The specific diurnal meteorological conditions of the 3 days were shown in Figure 2. Two water treatments were arranged: well-watered (WW) and drought stress (DS) conditions, with soil water content being $75 \%$ and $50 \%$ of field water holding capacity (FC), respectively. Water withholding for the two treatments was conducted by the weighing method. The plants were watered daily to restore the initial soil water content, between 1 and $2 \mathrm{~h}$ after sunset. Water withholding was kept for $30 \mathrm{~d}$ from April 6 through May 6. During water treatment periods, rain-shelter was used to prevent the rain on rainy days and was kept rolled up on sunny days to allow the crops to grow in the open-air conditions.

\subsection{Leaf gas exchange measurements}

The youngest fully expanded leaves of the main tiller were measured for measuring the diurnal variation of gas exchange parameters under LRH, MRH and HRH from 8:00 to 18:00 with the 2 hours interval, utilizing a Licor-6400 portable infrared gas analyzer (LI-COR Inc., Lincoln, Nebraska USA). For each replication, the leaves of three plants were measured and averaged as the value for each time span. With one measurement, 3 parameters concerned, including $g_{\mathrm{s}}, P_{\mathrm{N}}, T r$, were obtained in the meanwhile. To eliminate the disturbance to PAR from cloud cover and shading of neighboring leaves, PAR was set as the average value of 5 days in April or May for each time span. And chamber T was set as the same as the air temperature outside the chamber. Relative air humidity could not be set for Li-cor-6400 gas analyzer, RH of the air flowing into the chamber was as same as the air RH. At the same time with diurnal measurement of gas exchange parameters, 4 atmospheric factors were also determined. Air temperature and Relative air humidity were monitored once per minute by an automated temperature and relative humidity system (TH12R, Miaoxin, CN). VPD was calculated by T and $\mathrm{RH}$ as follows.

$$
\mathrm{VPD}=\square 1 \square \mathrm{RH} \square \times 0.6108 \times \mathrm{e}^{\frac{17.27 \times \mathrm{T}}{\mathrm{T}+273.3}}
$$

For investigating the relationships between $g_{\mathrm{s}}$ with $P_{\mathrm{N}}$ and $T r$ across genotypes under identical soil water and meteorological conditions, leaf gas exchange parameters were measured with 6 different genotypes under two water treatments at 9:30-11:00am on April 16, 29, and May 
166

167

168

169

170

171

172

173

5, 2018, the LRH (16.4\%), MRH (25.9\%), and HRH (37.8\%) day respectively. The same gas analyzer described above were used, with the leaf chamber conditions being set at the same temperature of $25^{\circ} \mathrm{C}, \mathrm{PAR}$ of $1000 \mu \mathrm{mol} \cdot \mathrm{m}^{-2} \cdot \mathrm{s}^{-1}$.

\subsection{Statistical analysis}

The collected data were statistically analyzed by SAS software (SAS 9.4, Cary, NC, USA). A Pearson correlation analysis was used to assess correlations between parameters. Signifcance was considered at $\mathrm{P}<0.05$ and 0.01 . Data were presented as means \pm standard errors $(\mathrm{n}=3)$.

\section{RESULTS}

\subsection{Main meteorological factors responsible for the diurnal variation of stomatal} conductance

The four meteorological factors, T, RH, VPD, and PAR interact and associate with each other. Each factor might directly affect $g_{\mathrm{s}}$, also indirectly affect $g_{\mathrm{s}}$ through other factors. Path analysis was carried out to clarify the correlations of four terms with $g_{\mathrm{s}}$ and their direct and indirect effects on $g_{\mathrm{s}}$ during diurnal dynamic variation. Table 2 showed how $g_{\mathrm{s}}$ related to diurnally varying atmospheric factors depended on moisture regimes. All the 4 factors had a much higher correlation with $g_{\mathrm{s}}$ under HRH than that under LRH and MRH. The correlation between $g_{\mathrm{s}}$ and the four factors tended to be higher under WW than that under DS when RH was the same level. Of the four factors, $g_{\mathrm{s}}$ was significantly correlated with T and PAR under all the regimes except DS+MRH. All the 4 factors were not correlated with $g_{\mathrm{s}}$ under DS+MRH. Temperature had a rather higher direct effect than RH and PAR on $g_{\mathrm{s}}$. And other factors had a much higher indirect effect on $g_{\mathrm{s}}$ through VPD and T on $g_{\mathrm{s}}$.

\subsection{Main factors responsible for the diurnal variation of transpiration rate}

Stomatal conductance and the four main meteorological factors T, RH, VPD, and PAR were closely related to each other. Path analysis was conducted to clarify the correlations between $\mathrm{Tr}$ and the 5 factors, the direct effect and indirect effect through other factors on $\operatorname{Tr}$ during their diurnal dynamic variation (Table 3 ).

Under LRH, $\operatorname{Tr}$ was highly correlated with $g_{\mathrm{s}}$ under both WW and DS, with higher direct effect coefficient $(\mathrm{DPC}=0.7346)$ and a higher negative indirect effect through VPD and a 
194

195

196

197

198

199

200

201

202

203

204

205

206

207

208

209

210

211

212

213

214

215

216

217

218

219

220

221

222

223

224

225

226

positive indirect effect through $\mathrm{T}$ under WW, with higher direct effect $(\mathrm{DPC}=0.8225)$ and a weak indirect effect through other factors under DS. Transpiration rate was also significantly correlated with T, RH, and VPD under WW. The temperature had a higher positive direct effect and a higher negative indirect effect through VPD on $T r$. Relative air humidity had a relatively lower direct effect and a higher negative indirect effect through $\mathrm{T}$ and a higher positive indirect effect through VPD on Tr. Vapor pressure deficit had a higher direct effect and a higher indirect effect through $\mathrm{T}$ on $\mathrm{Tr}$. All the 4 meteorological factors had a lower indirect effect through $g_{\mathrm{s}}$ on $\operatorname{Tr}$.

Under MRH, $\operatorname{Tr}$ had an extremely significant correlation with all the 5 factors, with the correlation between $T r$ and $g_{\mathrm{s}}$ being much higher, that between $\mathrm{Tr}$ and $\mathrm{RH}$ being negative, and that between $\operatorname{Tr}$ and T, VPD, and PAR being positive. Stomatal conductance had a rather higher direct effect than the indirect effect through any other factors on Tr. Of the 4 meteorological factors, VPD had the highest direct effect, and T, RH, and PAR had a higher indirect effect through VPD on $T r$. The indirect effect of 4 meteorological factors through $g_{\mathrm{s}}$ on $\operatorname{Tr}$ was rather smaller.

Under HRH, $\operatorname{Tr}$ was not correlated with $g_{\mathrm{s}}$ but significantly correlated with the 4 meteorological factors except PAR under WW. Vapor pressure deficit had the largest direct effect, while PAR had the smallest direct effect on $\operatorname{Tr}$ under DS. The indirect effect of T, RH, and PAR on Tr through VPD was the largest, with that of RH being negative, and that of T and PAR being positive. The indirect effect through $g_{\mathrm{s}}$ of the 4 meteorological factors on $\operatorname{Tr}$ was rather smaller.

\subsection{Stomatal conductance bear no correlation with transpiration rate in the diurnal change}

\section{under HRH}

The meteorological factors, such as T, RH, and VPD, etc., vary with time diurnally. Meteorological conditions were considered to be identical for different genotypes under the same measurement time span (9:30-11:00am). Across different genotypes, $g_{\mathrm{s}}$ had extremely significant correlations with $P_{\mathrm{N}}$ and $T r$ under identical meteorological conditions and soil water status (Table 4). The correlations between $g_{\mathrm{s}}$ and $T r$ under WW were lower than those under DS in the three different RH conditions. For the case of LRH, the correlations under WW were lower than those under DS. While for MRH and HRH, the correlation between $g_{\mathrm{s}}$ and $P_{\mathrm{N}}$ was higher under WW than that under DS. On the other hand, the correlations among $g_{\mathrm{s}}$ with $P_{\mathrm{N}}$ and $T r$ in the diurnal dynamics were investigated with 6 genotypes individually under WW and DS conditions (Table 5). There were the same results in WW and DS whether respectively or collectively. 
227 Stomatal conductance was closely correlated with $P_{\mathrm{N}}$ and $T r$ under LRH and MRH. Interestingly, 228 though $g_{\mathrm{s}}$ was still closely correlated with $P_{\mathrm{N}}$, it did not significantly correlate with $\operatorname{Tr}$ for each 229 genotype under HRH in the diurnal variation. This proved the high dependency between $g_{\mathrm{s}}$ and $230 P_{\mathrm{N}}$, also revealed the minor role of $g_{\mathrm{s}}$ on determining $\operatorname{Tr}$ diurnal variation under HRH. It might 231 be other factors, mainly the meteorological factors, that predominantly control $\operatorname{Tr}$ in the diurnal 232 variation in such case.

\section{DISCUSSION}

\subsection{Factors influencing the diurnal variation of stomatal conductance and transpiration}

rate

Stomata adjust aperture in response to environmental factors, such as soil water stress and atmospheric factors, as reported by many studies (Xu et al. 2016; Hernandez-Santana et al. 2016). The present study aimed at the relations between $g_{\mathrm{s}}$ of wheat with the influencing factors during the diurnal dynamic variation, and found that the relations was associated closely with RH. Stomatal conductance was not correlated with RH and VPD under LRH+DS and MRH+DS regimes, but highly correlated with the two factors under HRH. Moreover, stomatal conductance displayed a higher correlation with the influencing factors under WW than under DS. Thus, it seems that only when $g_{\mathrm{s}}$ of wheat was relatively higher in the case of high air RH and soil moisture, it was closely related to atmospheric factors during the diurnal variation. The reduced stomatal aperture could not respond to diurnally varying factors sensitively under dry soil and air moisture, which explain the rather lower correlation between them. Stomatal conductance of wheat was significantly correlated with PAR in most of the regimes. Sabir \& Yazar (2015) found that $g_{\mathrm{s}}$ was better correlated with PAR for all the tested grapevines cultivars than the other measured meteorological parameters, including $\mathrm{RH}$ and $\mathrm{T}$, etc. This is consistent with the case under DS+LRH and WW+MRH in our study, implying that sunlight had a significant effect on stomatal diurnal response under the two regimes.

Transpiration rate is controlled by the plant itself through stomatal adjustment on one hand. As a passive diffusion process of water, it was also regulated by surrounding factors, such as $\mathrm{T}$, $\mathrm{RH}$, and solar radiation intensity (Yang et al. 2012). Which factors mainly restrict $\operatorname{Tr}$ during the diurnal variation depended on $\mathrm{RH}$, as the present study showed. Higher correlation between $g_{\mathrm{s}}$ and $T r$ of wheat existed under LRH and MRH, but no correlation under HRH. This might imply that increased $g_{\mathrm{s}}$ under HRH was not restricting factors for $T r$, instead, atmospheric factors restricted $\operatorname{Tr}$ in this case. While reduced $g_{\mathrm{s}}$ became the main limiting factor for $\operatorname{Tr}$ under lower 
259

260

261

262

263

264

265

266

267

268

269

270

271

272

273

274

275

276

277

278

279

280

281

282

283

284

285

286

287

288

289

290

291

RH. Vapor pressure deficit had the highest direct effect of the four atmospheric factors, and other factors had the highest indirect effect through VPD under almost all the regimes.

\subsection{Correlations between stomatal conductance with transpiration rate and photosynthesis}

\section{rate in the diurnal dynamics}

Across different genotypes under identical meteorological conditions and soil water status, extremely significant correlations existed between $g_{\mathrm{s}}$ with $P_{\mathrm{N}}$ and $T r$, as reported by some previous studies (Wong, Cowan \& Farquhar 1979; McAusland et al. 2016). This indicates the important contribution of cultivars with different stomatal traits to photosynthesis and transpiration, and in turn to yield formation and water consumption, in the case of identical environmental conditions.

During the diurnal dynamics, $g_{\mathrm{s}}$ was significantly correlated with $\operatorname{Tr}$ in all the wheat genotypes tested under LRH and MRH, but not under HRH (Table 5), indicating the correlation between them depended on RH. As a physical process of water passive diffusion, transpiration is not only controlled by the plant itself through stomatal adjustment but also driven by soil moisture and atmospheric factors. In some cases, $T r$ is mainly regulated by RH or VPD, instead of $g_{\mathrm{s}}$. Devi et al. (2010) found that $T r$ increased over VPD rising, with a break point occurring in some genotypes above which there was little or no further increase in $\operatorname{Tr}$ of peanut. Stomatal conductance declined with VPD increasing (Leonardi, Guichard \& Bertin 2000; Talbott, Rahveh \& Zeiger 2003), or RH declining (Fanourakis et al. 2016; Fanourakis et al. 2019), which implied that $\operatorname{Tr}$ did not decline with $g_{\mathrm{s}}$ reducing, but increased with VPD rising. And the occurrence of $T r$ breakpoint might be due to that $g_{\mathrm{s}}$ continuously declined and turned to be the restricting factor of Tr. Also, Aliniaeifard et al. (2016) conducted an experiment with Chrysanthemum morifolium plants in the growth chamber. Similarly, they found higher $g_{\mathrm{s}}$ but lower $\operatorname{Tr}$ under low VPD (high $\mathrm{RH}$ ) in comparison with growth under moderate VPD. Consistently, Giday et al. (2015) found cultivar differences in plant transpiration rate at high relative air humidity were not related to genotypic variation in stomatal responsiveness. The transpiration rate did not increase with $g_{\mathrm{s}}$ rising but lowered down with increased RH. These indicated that it was VPD but not $g_{\mathrm{s}}$ that controlled $\operatorname{Tr}$ in such cases. Whether $g_{\mathrm{s}}$ is closely related to $\operatorname{Tr}$ depends on if $g_{\mathrm{s}}$ is restricting $\operatorname{Tr}$ under the specific circumstance. In the present study, the correlation coefficients between $g_{\mathrm{s}}$ and $\operatorname{Tr}$ of wheat under LHR and HRH were contrasting (Table 5). This might be ascribed to the different limiting effects of $g_{\mathrm{s}}$ on $\mathrm{Tr}$. Stomatal conductance went down and turned to be the limiting factor of $T r$ under LRH. While enhanced $g_{\mathrm{s}}$ is no more a limiting factor of $\operatorname{Tr}$ under HRH, and weakly correlated with $T r$. It might be either the regulating and limiting effect of $g_{\mathrm{s}}$ to 
292

293

294

295

296

297

298

299

300

301

302

303

304

305

306

307

308

309

310

311

312

313

314

315

316

317

318

319

320

321

322

323

324

$\operatorname{Tr}$ or the synchronous response of $g_{\mathrm{s}}$ and $\operatorname{Tr}$ to the atmospheric factors that result in the high correlation between $g_{\mathrm{s}}$ and $\operatorname{Tr}$ under MRH.

Stomatal conductance was highly correlated with $P_{\mathrm{N}}$ of wheat in the diurnal dynamics for each genotype, also across different genotypes at identical environmental conditions, highlighting the strong dependency between photosynthesis and stomatal regulation. However, as reported, stomata did not respond to environmental cues with $P_{\mathrm{N}}$ synchronously, but an order of magnitude slower than $P_{\mathrm{N}}$ (Lawson \& Blatt 2014). The lag in stomatal behavior and the temporal disconnect between $P_{\mathrm{N}}$ and $g_{\mathrm{s}}$ challenge the notion that stomata adjust the aperture to regulate $P_{\mathrm{N}}$. Moreover, Mott (1988) reported that it was $\mathrm{CO}_{2}$ concentration inside the leaf (Ci) rather than that outside the leaf influenced stomatal aperture. Afterwards, series of studies carried out by Roelfsema et al. $(2002 ; 2006)$ found that red light-induced stomatal opening is mediated by the reduction of $\mathrm{Ci}$ which is in turn caused by the increased photosynthetic activity of mesophyll cell. A recent study in maize (Zea mays L.) identified $2 \mathrm{Ca}$ genes which encode carbonic anhydrase mediated the response of plants to increased Ci (Kolbe et al. 2018). As an organism of high auto-regulation, plants respond to environmental cues positively within its adaptation limits. Under some specific circumstances, photosynthesis, the initiative anabolism process, might be capable of regulating $g_{\mathrm{s}}$ according to its demand for $\mathrm{CO}_{2}$ through affecting $\mathrm{Ci}$, though $g_{\mathrm{s}}$ has been proved to be a limiting factor of photosynthesis by most studies (Carmo-Silva et al. 2012; Chastain et al. 2014).

\section{CONCLUSIONS}

Relative air humidity played an important role in affecting the correlation between $g_{\mathrm{s}}$ with $P_{\mathrm{N}}$ and $T r$ of wheat during the diurnal variation. The transpiration rate was not significantly correlated with $g_{\mathrm{s}}$ but mainly affected by the atmospheric factors under HRH. In particular, VPD had a rather higher direct and indirect effect on $T r$. The notion that stomata continuously adjust aperture in response to environmental factors to optimize the trade-off between photosynthesis and water loss was challenged. Thus the definite interrelationship among $P_{\mathrm{N}}, T r$, and $g_{\mathrm{s}}$ of wheat need to be elucidated conditionally. In these cases that $g_{\mathrm{s}}$ is not the key influential factor for $T r$, any efforts to artificially reduce $g_{\mathrm{s}}$ of wheat may not contribute significantly to water saving, but pay the price of photosynthetic reduction and yield loss. But when meteorological and soil water conditions were identical, $g_{\mathrm{s}}$ was significantly correlated with $\operatorname{Tr}$ and $P_{\mathrm{N}}$ across different genotypes. Thus, to select and adopt appropriate wheat cultivars with specific stomata traits is undoubtedly a good strategy for realizing water saving. Taking yield issue into account, genotype adoption has to compromise the requirement for yield and water saving, and needs to 
325

326

327

328

329

330

331

332

333

match the water availability of areas with stomatal sensitivity of wheat genotypes to water stress.

\section{ACKNOWLEDGMENTS}

This work was supported by a grant from The National Key Research and Development Program (2017YFD0201702).

\section{REFERENCES}

Aliniaeifard S, and van Meeteren U. 2016. Stomatal characteristics and desiccation response of leaves of cut chrysanthemum (Chrysanthemum morifolium) flowers grown at high air humidity. Scientia Horticulturae 205:84-89. https://doi.org/10.1016/j.scienta.2016.04.025

Assmann SM, and Wang XQ. 2001. From milliseconds to millions of years: guard cells and environmental responses. Current opinion in plant biology 4:421-428. https://doi.org/10.1016/S1369-5266(00)00195-3

Bakker JC. 1991a. Effects of humidity on stomatal density and its relation to leaf conductance. Scientia Horticulturae 48:205-212. https://doi.org/10.1016/0304-4238(91)90128-L

Bakker JC. 1991b. Leaf conductance of four glasshouse vegetable crops as affected by air humidity. Agricultural \& Forest Meteorology 55:23-36. https://doi.org/10.1016/01681923(91)90020-Q

Belko N, Zaman-Allah M, Cisse N, Diop NN, Zombre G, Ehlers JD, and Vadez V. 2012. Lower soil moisture threshold for transpiration decline under water deficit correlates with lower canopy conductance and higher transpiration efficiency in drought-tolerant cowpea. Functional Plant Biology 39:306-322. https://doi.org/10.1071/FP11282

Carmo-Silva AE, Gore MA, Andrade-Sanchez P, French AN, Hunsaker DJ, and Salvucci ME. 2012. Decreased $\mathrm{CO}_{2}$ availability and inactivation of Rubisco limit photosynthesis in cotton plants under heat and drought stress in the field. Environmental and Experimental Botany 83:1-11. https://doi.org/10.1016/j.envexpbot.2012.04.001

Chastain DR, Snider JL, Collins GD, Perry CD, Whitaker J, and Byrd SA. 2014. Water deficit in field-grown Gossypium hirsutum primarily limits net photosynthesis by decreasing stomatal conductance, increasing photorespiration, and increasing the ratio of dark respiration to gross photosynthesis. Journal of Plant Physiology 171:1576-1585. 
353

354

355

356

357

358

359

360

361

362

363

364

365

366

367

368

369

370

371

372

373

374

375

376

377

378

379

380

381

382

383

https://doi.org/10.1016/j.jplph.2014.07.014

de Dios VR, Gessler A, Ferrio JP, Alday JG, Bahn M, del Castillo J, Devidal S, Garcia-Munoz S, Kayler Z, Landais D, Martin-Gomez P, Milcu A, Piel C, Pirhofer-Walzl K, Ravel O, Salekin S, Tissue DT, Tjoelker MG, Voltas J, and Roy J. 2016. Circadian rhythms have significant effects on leaf-to-canopy scale gas exchange under field conditions. Gigascience 5:43. https://doi.org/10.1186/s13742-016-0149-y

Devi MJ, Sinclair TR, and Vadez V. 2010. Genotypic variation in peanut for transpiration response to vapor pressure deficit. Crop Science 50:191-196. https://doi.org/10.2135/cropsci2009.04.0220

Dodd AN, Salathia N, Hall A, Kevei E, Toth R, Nagy F, Hibberd JM, Millar AJ, and Webb AAR. 2005. Plant circadian clocks increase photosynthesis, growth, survival, and competitive advantage. Science 309:630-633. https://doi.org/10.1126/science.1115581

Fanourakis D, Bouranis D, Giday H, Carvalho DR, Nejad AR, and Ottosen CO. 2016. Improving stomatal functioning at elevated growth air humidity: a review. Journal of plant physiology, 207:51-60. http://dx.doi.org/10.1016/j.jplph.2016.10.003

Fanourakis D, Giday H, Hyldgaard B, Bouranis D, Körner O, and Ottosen, CO. 2019. Low air humidity during cultivation promotes stomatal closure ability in rose. European Journal of Horticultural Science, 84:245-252. https://doi.org/10.17660/eJHS.2019/84.4.7

Farquhar GD, and Sharkey TD. 1982. Stomatal Conductance and Photosynthesis. Annual review of plant physiology 33:317-345.

Giday H, Kjær K H, Ottosen C O, and Fanourakis D. 2013. Cultivar differences in plant transpiration rate at high relative air humidity are not related to genotypic variation in stomatal responsiveness, VI International Symposium on Rose Research and Cultivation 1064: 99-106. https://doi.org/10.17660/ActaHortic.2015.1064.12

Haque MS, de Sousa A, Soares C, Kjaer KH, Fidalgo F, Rosenqvist E, and Ottosen CO. 2017. Temperature variation under continuous light restores tomato leaf photosynthesis and maintains the diurnal pattern in stomatal conductance. Frontiers in Plant Science 8:1602. https://doi.org/10.3389/fpls.2017.01602

Hassidim M, Dakhiya Y, Turjeman A, Hussien D, Shor E, Anidjar A, Goldberg K, and Green RM. 2017. CIRCADIAN CLOCK ASSOCIATED1 (CCA1) and the Circadian Control of Stomatal Aperture. Plant Physiology 175:1864-1877. 
384

385

386

387

388

389

390

391

392

393

394

395

396

397

398

399

400

401

402

403

404

405

406

407

408

409

410

411

412

413

https://doi.org/10.1104/pp.17.01214

Hernandez-Santana V, Fernandez JE, Rodriguez-Dominguez CM, Romero R, and Diaz-Espejo A. 2016. The dynamics of radial sap flux density reflects changes in stomatal conductance in response to soil and air water deficit. Agricultural and Forest Meteorology 218:92-101. https://doi.org/10.1016/j.agrformet.2015.11.013

Hetherington AM, and Woodward FI. 2003. The role of stomata in sensing and driving environmental change. Nature 424:901-908. https://doi.org/10.1038/nature01843

Kholová J, Hash CT, Kakkera A, Kocova M, and Vadez V. 2010a. Constitutive waterconserving mechanisms are correlated with the terminal drought tolerance of pearl millet [Pennisetum glaucum (L.) R. Br.]. Journal of Experimental Botany 61:369-377. https://doi.org/10.1093/jxb/erp314

Kholová J, Hash CT, Kumar PL, Yadav RS, Kočová M, and Vadez V. 2010b. Terminal droughttolerant pearl millet [Pennisetum glaucum (L.) R. Br.] have high leaf ABA and limit transpiration at high vapour pressure deficit. Journal of Experimental Botany 61:14311440. https://doi.org/10.1104/pp.17.01214

Kolbe AR, Brutnell TP, Cousins AB, and Studer AJ. 2018. Carbonic anhydrase mutants in Zea mays have altered stomatal responses to environmental signals. Plant Physiology 177:980-989. https://doi.org/10.1104/pp.18.00176

Lawson T, and Blatt MR. 2014. Stomatal size, speed, and responsiveness impact on photosynthesis and water use efficiency. Plant Physiology 164:1556-1570. https://doi.org/10.1104/pp.114.237107

Leonardi C, Guichard S, and Bertin N. 2000. High vapour pressure deficit influences growth, transpiration and quality of tomato fruits. Scientia Horticulturae 84:285-296. https://doi.org/10.1016/S0304-4238(99)00127-2

McAusland L, Vialet-Chabrand S, Davey P, Baker NR, Brendel O, and Lawson T. 2016. Effects of kinetics of light-induced stomatal responses on photosynthesis and water-use efficiency. New Phytologist 211:1209-1220. https://doi.org/10.1111/nph.14000

Mei XR, Zhong XL, Vincent V, and Liu XY. 2013. Improving water use efficiency of wheat crop varieties in the North China Plain: Review and analysis. Journal of Integrative Agriculture 12:1243-1250. https://doi.org/10.1016/S2095-3119(13)60437-2 
414

415

416

417

418

419

420

421

422

423

424

425

426

427

428

429

430

431

432

433

434

435

436

437

438

439

440

441

442

443

Merilo E, Yarmolinsky D, Jalakas P, Parik H, Tulva I, Rasulov B, Kilk K, and Kollist H. 2018. Stomatal VPD response: there is more to the story than ABA. Plant Physiology 176:851864. https://doi.org/10.1104/pp.17.00912

Mott KA. 1988. Do stomata respond to $\mathrm{CO}_{2}$ concentrations other than intercellular? Plant Physiology 86:200-203. https://doi.org/10.1104/pp.86.1.200

Roelfsema MRG, Hanstein S, Felle HH, and Hedrich R. 2002. $\mathrm{CO}_{2}$ provides an intermediate link in the red light response of guard cells. Plant Journal 32:65-75. https://doi.org/10.1046/j.1365-313X.2002.01403.x

Roelfsema MRG, Konrad KR, Marten H, Psaras GK, Hartung W, and Hedrich R. 2006. Guard cells in albino leaf patches do not respond to photosynthetically active radiation, but are sensitive to blue light, $\mathrm{CO}_{2}$ and abscisic acid. Plant Cell and Environment 29:1595-1605. https://doi.org/10.1111/j.1365-3040.2006.01536.x

Sabir A, and Yazar K. 2015. Diurnal dynamics of stomatal conductance and leaf temperature of grapevines (Vitis vinifera L.) in response to daily climatic variables. Acta Scientiarum Polonorum-Hortorum Cultus 14:3-15.

Suzuki M, Umeda H, Matsuo S, Kawasaki Y, Ahn D, Hamamoto H, and Iwasaki Y. 2015. Effects of relative humidity and nutrient supply on growth and nutrient uptake in greenhouse tomato production. Scientia Horticulturae 187:44-49. https://dx.doi.org/10.1016/j.scienta.2015.02.035

Talbott LD, Rahveh E, and Zeiger E. 2003. Relative humidity is a key factor in the acclimation of the stomatal response to $\mathrm{CO}_{2}$. Journal of Experimental Botany 54:21412147.https://doi.org/10.1093/jxb/erg215

Wong S, Cowan I, and Farquhar G. 1979. Stomatal conductance correlates with photosynthetic capacity. Nature 282:424.

Xu ZZ, Jiang YL, Jia BR, and Zhou GS. 2016. Elevated- $\mathrm{CO}_{2}$ response of stomata and its dependence on environmental factors. Frontiers in Plant Science 7:657. https://doi.org/10.3389/fpls.2016.00657

Yang Z, Sinclair TR, Zhu M, Messina CD, Cooper M, and Hammer GL. 2012. Temperature effect on transpiration response of maize plants to vapour pressure deficit. Environmental and Experimental Botany 78:157-162. https://doi.org/10.1016/j.envexpbot.2011.12.034 
444 Yin ZH, and Johnson GN. 2000. Photosynthetic acclimation of higher plants to growth in

445

446

447

448

449

450

451

452

453

454

455

456 fluctuating light environments. Photosynthesis Research 63:97-107. https://doi.org/10.1023/A:1006303611365

Yoshimoto M, Oue H, and Kobayashi K. 2005. Energy balance and water use efficiency of rice canopies under free-air $\mathrm{CO}_{2}$ enrichment. Agricultural and Forest Meteorology 133:226246. http://dx.doi.org/10.1016\%2Fj.agrformet.2005.09.010

Zhang XY, Pei D, and Hu CS. 2003. Conserving groundwater for irrigation in the North China Plain. Irrigation Science 21:159-166. https://doi.org/10.1007/s00271-002-0059-x

Zhang XY, Wang YJ, Huang GR, Feng F, Liu XY, Guo R, Gu FX, Hu X, Yang ZG, Zhong XL and Mei XR. 2019. Atmospheric humidity and genotype are key determinants of the diurnal stomatal conductance pattern. Journal of Agronomy and Crop Science 00:1-8. https ://doi.org/10.1111/jac.12375 
Table $\mathbf{1}$ (on next page)

Genotypes' names and associated details 
1

\begin{tabular}{lccc}
\hline \multicolumn{1}{c}{ Genotype } & Year of release & Breeding place & Pedigree \\
\hline Jing 411 & 1993 & Beijing & Fengkang $2 /$ Changfeng 1 \\
12 Song 1 & line & Henan & LK 906/Yan 7961 \\
Jinmai 47 & 1998 & Shanxi & 12057//Han 522/K37-20 \\
Lankaoaizao 8 & 2003 & Henan & Lankao 84(184)1/Lankao 90 \\
Chang 6878 & 2003 & Shanxi & Linhan 5175/Jinmai 63 \\
Zhoumai 18 & 2005 & Henan & Neixiang 185/Zhoumai 9 \\
\hline
\end{tabular}




\section{Table 2 (on next page)}

\section{Path analysis of stomatal conductance with meteorological factors during diurnal dynamic} variation

The measurement dates and diurnal meteorological conditions are shown in Figure 2. T, air temperature ; $\mathrm{RH}$, relative air humidity ; VPD , vapor pressure deficit ; PAR, photosynthetically active radiation; WW, soil well-watered; DS, soil drought stress; LRH, low er relative air humidity; MRH, moderate relative air humidity; $\mathrm{HRH}$, high er relative air humidity. The daily average relative air humidity of $\mathrm{LRH}, \mathrm{MRH}$ and $\mathrm{HRH}$ were $15.4 \%, 28.3 \%$ and $36.7 \%$ respectively. ${ }^{* *}$, significant differen ce at $p<0.01 ;{ }^{*}$, signi fi cant difference at $p$ $<0.05$. 


\begin{tabular}{|c|c|c|c|c|c|c|c|}
\hline \multirow{2}{*}{ Regimes } & \multirow{2}{*}{$\begin{array}{c}\text { Independent } \\
\text { variable }\end{array}$} & \multirow{2}{*}{$\begin{array}{l}\text { Direct path } \\
\text { coefficient }\end{array}$} & \multicolumn{4}{|c|}{ Indirect path coefficient } & \multirow{2}{*}{$\begin{array}{c}\text { Simple } \\
\text { correlation } \\
\text { coefficient }\end{array}$} \\
\hline & & & $\mathbf{T}$ & RH & VPD & PAR & \\
\hline \multirow{4}{*}{$\begin{array}{l}\text { WW } \\
\text { LRH }\end{array}$} & $\mathrm{T}$ & 1.8076 & & 1.1045 & -2.3004 & -0.3287 & $0.2830 * *$ \\
\hline & $\mathrm{RH}$ & -1.2985 & -1.5376 & & 2.1758 & 0.2603 & $-0.3999 * *$ \\
\hline & VPD & -2.3397 & 1.7773 & 1.2075 & & -0.3159 & $0.3291 * *$ \\
\hline & PAR & -0.3435 & 1.7297 & 0.9840 & -2.1519 & & $0.2183 *$ \\
\hline \multirow{4}{*}{ LRH } & $\mathrm{T}$ & $-7.4551 * *$ & & -1.8020 & 8.8615 & 0.1602 & $-0.2355^{*}$ \\
\hline & RH & $2.1159 * *$ & 6.3492 & & -8.3855 & -0.1270 & -0.0474 \\
\hline & VPD & $9.0120 * *$ & -7.3306 & -1.9688 & & 0.1540 & -0.1335 \\
\hline & PAR & 0.1675 & -7.1306 & -1.6041 & 8.2849 & & $-0.2824 * *$ \\
\hline \multirow{4}{*}{$\begin{array}{l}\text { WW } \\
\text { MRH }\end{array}$} & $\mathrm{T}$ & 0.0172 & & -0.3842 & 0.6178 & 0.0045 & $0.2553 *$ \\
\hline & $\mathrm{RH}$ & 0.4345 & -0.0152 & & -0.5996 & -0.0044 & -0.1847 \\
\hline & VPD & 0.6316 & 0.0168 & -0.4125 & & 0.0047 & $0.2406^{*}$ \\
\hline & PAR & 0.0051 & 0.0153 & -0.3711 & 0.5763 & & $0.2257 *$ \\
\hline \multirow{4}{*}{$\begin{array}{c}\text { DS } \\
\mathrm{MRH}\end{array}$} & $\mathrm{T}$ & $-1.6275^{*}$ & & -0.4768 & 2.0112 & 0.1741 & 0.0810 \\
\hline & RH & 0.5290 & 1.4669 & & -1.9455 & -0.1709 & -0.1205 \\
\hline & VPD & 2.0436 & -1.6017 & -0.5036 & & 0.1789 & 0.1172 \\
\hline & PAR & 0.1994 & -1.4211 & -0.4535 & 1.8332 & & 0.1580 \\
\hline \multirow{4}{*}{$\begin{array}{l}\text { WW } \\
\text { HRH }\end{array}$} & $\mathrm{T}$ & -0.3377 & & 0.1237 & -0.4543 & -0.0818 & $-0.7502 * *$ \\
\hline & RH & -0.1346 & 0.3103 & & 0.4425 & 0.0776 & $0.6959 * *$ \\
\hline & VPD & -0.4605 & -0.3332 & 0.1294 & & -0.0757 & $-0.7400 * *$ \\
\hline & PAR & -0.1288 & -0.2144 & 0.0812 & -0.2705 & & $-0.5325^{* *}$ \\
\hline
\end{tabular}




\begin{tabular}{cccccccc} 
& T & 2.0471 & & 1.0820 & -3.3811 & -0.2891 & $-0.5411^{* *}$ \\
DS & RH & -1.2121 & -1.8274 & & 3.3177 & 0.2236 & $0.5018^{* *}$ \\
& VPD & -3.4552 & 2.0031 & 1.1639 & & -0.2514 & $-0.5396^{* *}$ \\
& PAR & $-0.4298^{*}$ & 1.3769 & 0.6306 & -2.0211 & & $-0.4433^{* *}$ \\
\hline
\end{tabular}

1

2 


\section{Table $\mathbf{3}$ (on next page)}

Path analysis of transpiration rate with stomatal conductance and meteorological factors during diurnal dynamic variation

The measurement dates and diurnal meteorological conditions are shown in Figure $2 . g_{s}$, stomatal conductance; $T$, air temperature ; RH , relative air humidity ; VPD , vapor pressure deficit ; PAR, photosynthetically active radiation; WW, soil well-watered; DS, soil drought stress; LRH, low relative humidity; $\mathrm{MRH}$, moderate relative humidity; $\mathrm{HRH}$, high relative humidity. The daily average relative air humidity of $\mathrm{LRH}, \mathrm{MRH}$ and $\mathrm{HRH}$ were $15.4 \%, 28.3 \%$ and $36.7 \%$ respectively. ${ }^{*}$, significant difference at $\mathrm{p}<$ $0.01 ; *$, sign if icant difference at $p<0.05$. 


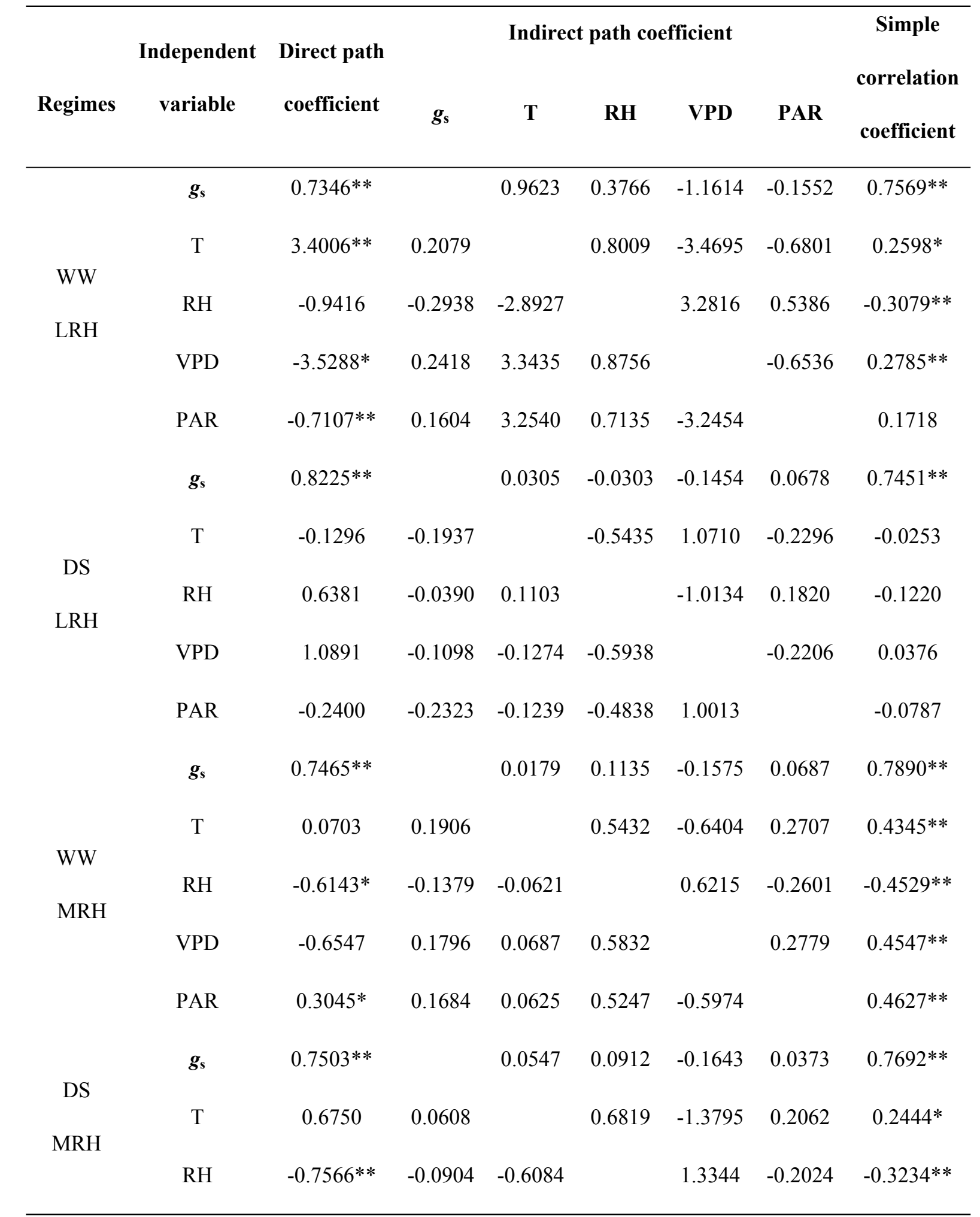

1 


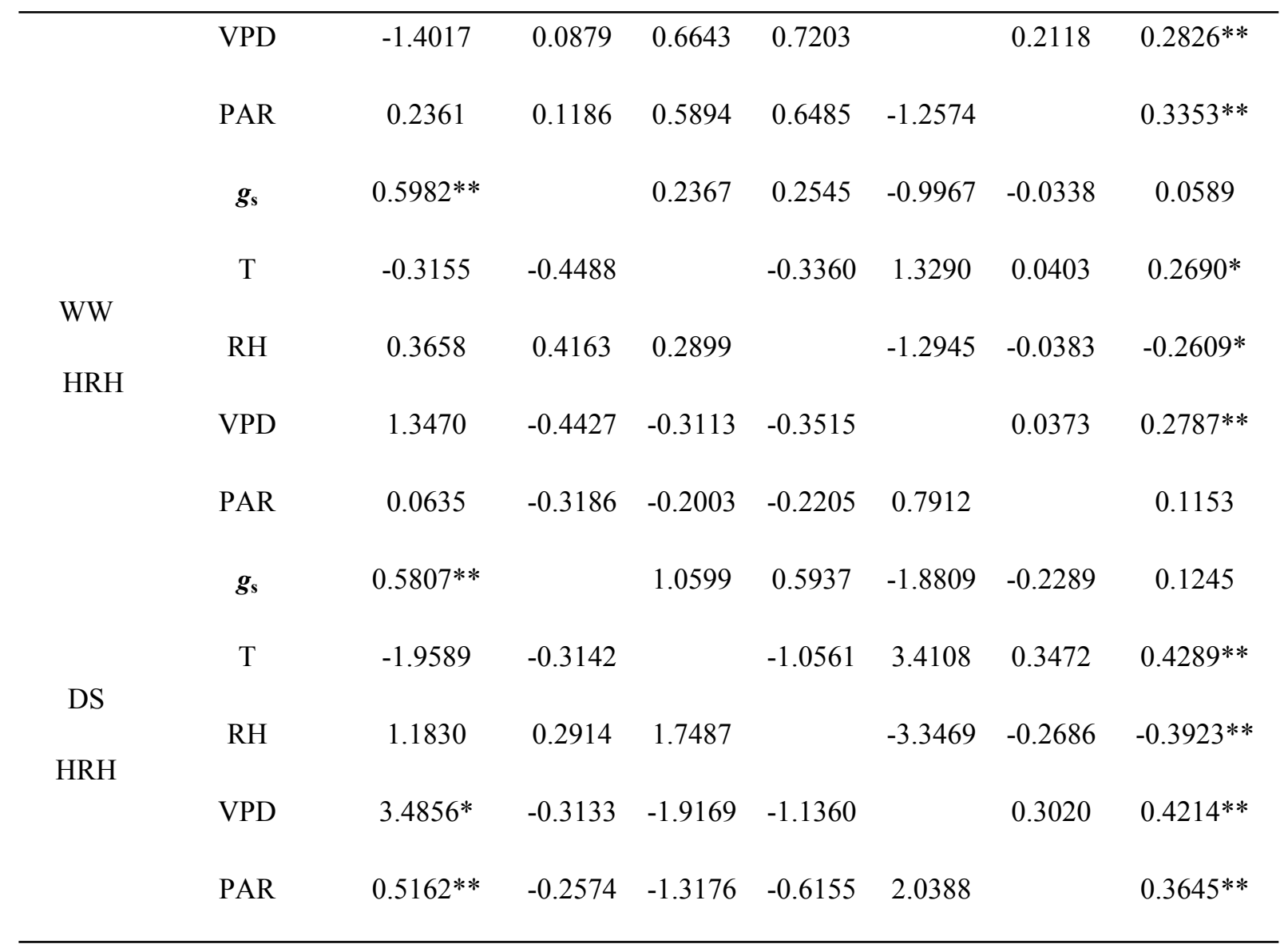

3 
Table 4(on next page)

\section{Correlations of stomatal conductance $\left(g_{s}\right)$ with net photosynthesis rate $\left(P_{N}\right)$ and transpiration rate ( $\mathrm{Tr}$ ) among six genotypes}

The measurements were conducted with 6 genotypes during 9:30-11:00 at each measurement day . WW , well-watered ; DS , drought stress ; LRH, low er relative air humidity; $\mathrm{MRH}$, moderate relative air humidity; $\mathrm{HRH}$, high er relative air humidity. The daily average relative air humidity of $\mathrm{LRH}, \mathrm{MRH}$ and $\mathrm{HRH}$ were $16.4 \%, 25.9 \%$, and $37.8 \%$ respectively. ${ }^{* *}$, significant difference at $p<0.01 ; *$, significant difference at $p$ $<0.05$. 
1

\begin{tabular}{|c|c|c|c|c|}
\hline \multirow{2}{*}{ Group } & \multicolumn{2}{|c|}{ WW } & \multicolumn{2}{|c|}{ DS } \\
\hline & $g \mathrm{~s}-P_{\mathrm{N}}$ & $g \mathrm{~s}-\mathrm{Tr}$ & $g \mathrm{~s}-P_{\mathrm{N}}$ & $g \mathrm{~s}-\mathrm{Tr}$ \\
\hline LRH & $0.9460 * *$ & $0.8968 * *$ & $0.9663 * *$ & $0.9820 * *$ \\
\hline $\mathrm{MRH}$ & $0.9100 * *$ & $0.9376^{* *}$ & $0.9096^{* *}$ & $0.9837 * *$ \\
\hline HRH & $0.9547 * *$ & $0.6741^{* *}$ & $0.8222 * *$ & $0.9491 * *$ \\
\hline
\end{tabular}


Table 5 (on next page)

\section{Correlations of stomatal conductance $\left(g_{s}\right)$ with net photosynthesis rate $\left(P_{N}\right)$ and transpiration rate ( $T r$ ) in diurnal dynamics of each genotype}

The measurement dates and diurnal meteorological conditions are shown in Figure 2 . LRH, low er relative air humidity; $\mathrm{MRH}$, moderate relative air humidity; $\mathrm{HRH}$, high er relative air humidity. The daily average relative air humidity of $\mathrm{LRH}, \mathrm{MRH}$ and $\mathrm{HRH}$ were $15.4 \%, 28.3 \%$ and $36.7 \%$ respectively. ${ }^{* *}$, significant different at $p<0.01$. 
1

\begin{tabular}{|c|c|c|c|c|c|c|}
\hline \multirow{2}{*}{ Genotype } & \multicolumn{2}{|c|}{ LRH } & \multicolumn{2}{|c|}{ MRH } & \multicolumn{2}{|c|}{ HRH } \\
\hline & $g \mathrm{~s}-P_{\mathrm{N}}$ & $g \mathrm{~s}-\mathrm{Tr}$ & $g \mathrm{~s}-P_{\mathrm{N}}$ & $g \mathrm{~s}-\mathrm{Tr}$ & $g \mathrm{~S}-P_{\mathrm{N}}$ & $g \mathrm{~s}-\mathrm{Tr}$ \\
\hline 12 Song & $0.9726 * *$ & $0.9441 * *$ & $0.7655^{* *}$ & $0.6879 * *$ & $0.8910^{* *}$ & 0.3538 \\
\hline Lankaoaizao 8 & $0.7316^{* *}$ & $0.7537 * *$ & $0.8859 * *$ & $0.8071^{* *}$ & $0.8437 * *$ & 0.2141 \\
\hline Jinmai 47 & $0.8771 * *$ & $0.9019 * *$ & $0.8042 * *$ & $0.8425^{* *}$ & $0.7184 * *$ & 0.2127 \\
\hline Chang 6878 & $0.8233^{* *}$ & $0.7739 * *$ & $0.8274 * *$ & $0.8633^{* *}$ & $0.7666^{* *}$ & 0.3450 \\
\hline Jing 411 & $0.9240 * *$ & $0.8909 * *$ & $0.5985 * *$ & $0.6794 * *$ & $0.8501 * *$ & 0.2251 \\
\hline Zhoumai 18 & $0.8453 * *$ & $0.8514 * *$ & $0.9162 * *$ & $0.9560 * *$ & $0.8163 * *$ & 0.1919 \\
\hline
\end{tabular}


Figure 1

The environmental condition during the 2017-2018 wheat growing season

The data are the total precipitation and the average values of air temperature in each month.

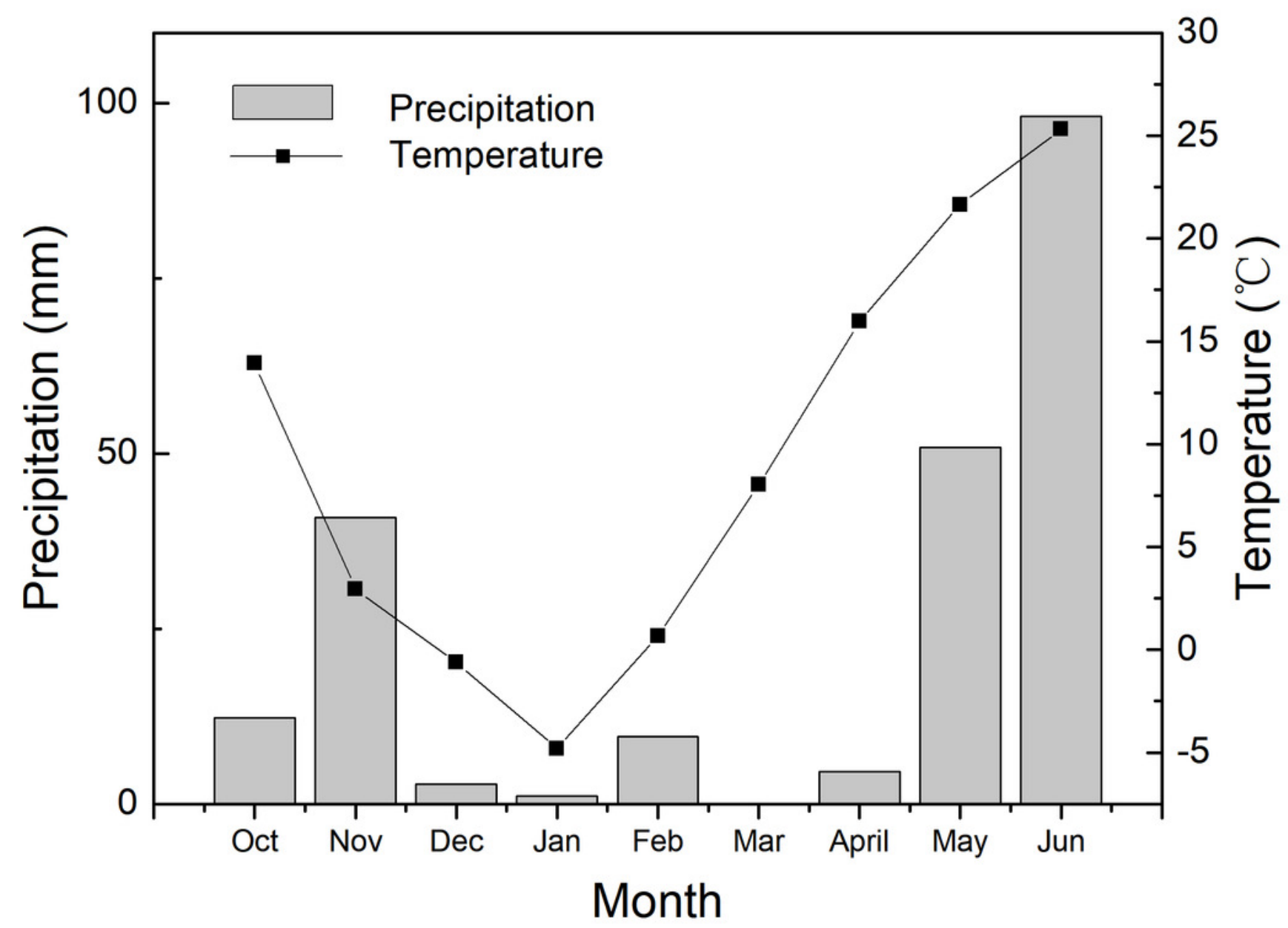


Figure 2

The diurnal meteorological conditions of measurement days

(A)Diurnal temperature ( $T$ ) condition of each measurement day. (B) Diurnal relative air humidity $(\mathrm{RH})$ condition of each measurement day. (C) Diurnal vapor pressure deficit (VPD) condition of each measurement day. (D) Diurnal photosynthetically active radiation (PAR) condition of each measurement day. Values represent means \pm standard errors $(n=3)$.

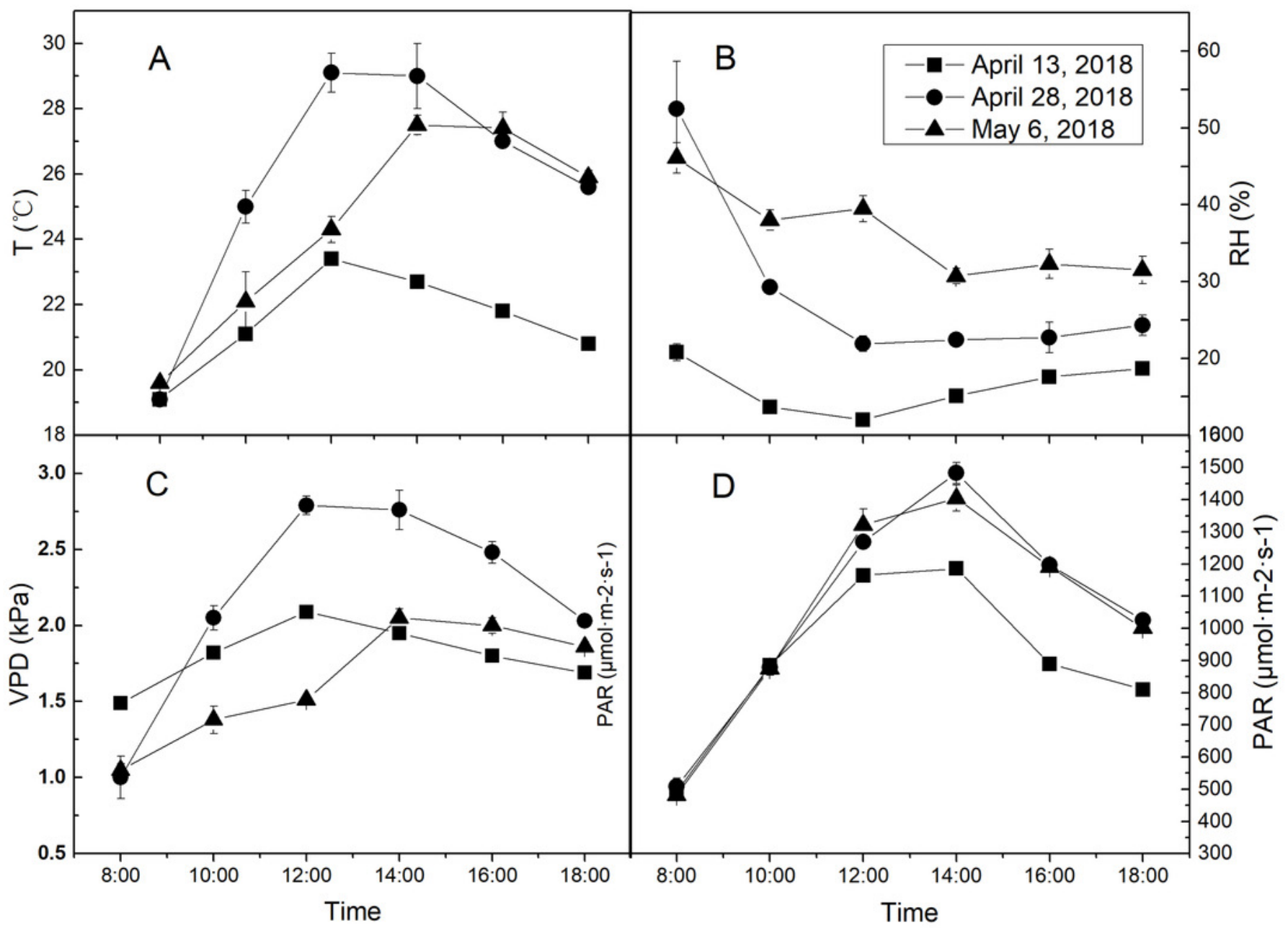

